Hakemli

\title{
E- SPOR VE E-SPOR HUKUKU'NDA SPORCU SÖZLEŞMELERİ
}

\author{
e-Sports and Sports Contracts in e-Sports Law
}

Hakkı Mert DOĞU*

\section{ÖZET}

Son yıllarda hızlı bir gelişim evresine giren spor ve spor hukuku, bu gelişimini sanal alemde de göstermektedir. E-spor (elektronik spor) adı altında ortaya çıkan ve genellikle internet üzerinden takım halinde ya da bireysel olarak oynanan bilgisayar oyunlarında kendini gösteren bu spor dalı, bütün dünyada özellikle gençleri etkisi altına almaktadır.

Sporun bütünleştirici özelliği, e-sporda daha sıkı bir şekilde hissedilmektedir. Espor aracılı̆̆ılyla dünyanın neresinde olursa olsun e-spor sporcuları internet üzerinden bağlantı kurabilmekte ve böylece sporun ana teması olan dostluklar kurulabilmektedir.

Çalışmada e-spor ile daha çok yeni olan e-spor hukuku kavramları üzerinde durulmakta ve genel bilgiler verilmektedir. Ardından e-spor hukuku kapsamında sporcu sözleşmelerinin nasıl olması gerektiği hususunda bazı fikirler ileri sürülmekte ve bu sayede e-spor hukuku alanına katkı sağlanmak istenmektedir. Hukuk

Anahtar Kelimeler: E-Spor, Spor Hukuku, Spor Sözleşmesi, E-Spor Hukuku,

\section{ABSTRACT}

Sports and sports law, which has entered a rapid development phase in recent years, shows its development in the virtual world. This sport, which occurs under the name of e-sports (electronic sports) and which is usually played on the internet as a team or individually, affects the young people all over the world.

Makalenin Gelis Tarihi: 26.10.2018, Makalenin Kabul Tarihi: 20.11.2018

Dr. Öğretim Üyesi, KTO Karatay Üniversitesi Hukuk Fakültesi Medeni Hukuk Ana Bilim Dalı, ORCID: 0000-0003-4695-9623 
The integrative feature of sport makes it feel more intense in e-sports. No matter where in the world via e-sports, e-sports athletes can connect via internet and thus friendships can be established as the main theme of the sport.

In this study, e-sports and e-sports law concepts are emphasized and general information is given. Then, there are some ideas about how sportsman contracts should be made within the scope of e-sports law and thus, it is desired to contribute to the field of e-sports law.

Keywords: E- Sport, Sports Law, Sports Contracts, E-Sports Law, Law

\section{GİRIŞ}

Spor, belirli kurallar çerçevesinde yapılan ve içinde çeşitli aktivitelerin bulunduğu faaliyetlere verilen genel addır ${ }^{1}$. Sporun bir hak olması ${ }^{2}$ ve gelişim göstermesiyle birlikte spor hukuku adı altında yeni bir hukuk dalı ortaya çıkmıştır. Spor Hukuku, sportif faaliyetlerin yanında spor süjeleri arasındaki ilişkileri düzenleyen genç ve karma bir hukuk dalıdır .

Teknolojideki hızlı ve durdurulamaz gelişim, spor alanında da kendisini göstermiş ve e-spor adı altında yeni bir spor branşı ortaya çıkmıştır. E-sporun, bir spor branşı olup olmadığı tartışmaları devam ederken, bütün dünyada etkisini gösteren ve kitleleri peşinden sürükleyen bu branş özellikle gençler arasındaki yayılımını günden

1 Bkz., ERTASS, Şeref/PETEK, Hasan; Spor Hukuku, Yetkin Yayınları, B.3, Ankara 2017, s. 31 vd.; GÜLŞEN, Recep; Spor Hukuku, Adalet Yayınevi, B.2, Ankara 2013, s. 3-4; ÇAĞLAYAN, Ramazan; Spor Hukuku (Spor Hukuku Temel Metinleri), Asil Yayın Dağıtım, Ankara 2007, s. 12; ERTEN, Rifat; Milletlerarası Özel Hukukta Spor, Adalet Yayınevi, Ankara 2007, s. 11; ERDEMLİ , Attilla; "Spor Nedir?", Spor Hukuku Dersleri, Ed: Kısmet Erkiner/Ali Soysüren, Kadir Has Üniversitesi Yayınları, 2007, s. 13 vd.; ERTEN, Rifat; "Türk Sporunun Yapısal Düzeni", Gazi Üniversitesi Hukuk Fakültesi Dergisi, C.X, S.1,2, 2006, s. 120, (Yapısal Düzen); KILCIGİL, Ertan; Sosyal Çevre-Spor İlişkileri (Teori ve Elit Sporculara İlişkin Bir Uygulama), Bağırgan Yayınevi, Ankara 1998, s. 6; TÜKENMEZ, Metin; Toplumbilim ve Spor, Kaynak Yayınları, B.2, İstanbul 2011, s. 32; AYDIN, Zübeyt; "Spor ve Spor Politikalarl”, Ankara Barosu Spor Hukuku Kurulu Av. Akın Ataksoy Armağanı, Ed: Tacar Çağlar, Afşaroğlu Matbaası, Ankara 2015, s. 178. Ayrica bkz., FRITZWEILER, Jochen/PFISTER, Bernhard/SUMMERER, Thomas; Praxishandbuch Sportrecht, C.H. Beck Verlag, 3. Aufl., 2014, s. 2 vd.

2 Sporun bir hak olduğu noktasında bkz., Bkz., ERTAŞ/PETEK, s. 49 vd.; ÇAĞLAYAN, s. $23 \mathrm{vd}$.

3 GENÇ, Durmuş Ali; Spor Hukuku, Alfa Basım Yayım Dağıtım, İstanbul 1998, s. 61; EKŞí, Nuray; Spor Tahkim Hukuku, Beta Basım Yayım Dağıtım, İstanbul 2015, s. 5; ERTAŞ/PETEK, s. 40; RİFAT, s. 55; ÇAĞLAYAN, s. 17. Spor Hukuku'nun boyutları için bkz., AKYILDIZ, Ali; "Sporun Hukuku ve Yargısı", Ömer Remzi Arıkan Armağanı, Ed: Tacar Çağlar, Mattek Matbaacılık, 2013, s. 62 vd. Spor Hukuku'na ilişkin olarak ayrıca bkz., ERKIINER, Kısmet; “Türkiye'de Spor Hukuku'nun Oluşumu”, İstanbul Barosu Dergisi-Spor Hukuku Özel Sayısı, 2007, s. 17 vd. 
güne arttırmaktadır. E-sporun ortaya çıkışı, onun bazı kurallar dahilinde yapılması ihtiyacını doğurduğundan ötürü yepyeni bir spor hukuku alt dalı olan $e$-spor hukuku ortaya çıkmıştır.

Çalışma iki ana bölümden oluşmaktadır. İlk bölümde e-spor ve e-spor hukuku üzerinde durulmuş; her iki kavramın tanımı verilmeye çalışılarak söz konusu kavramların tanınması ve anlaşılması hedeflenmiştir. İkinci bölümde ise e-spor hukukunda sporcu sözleşmeleri incelemeye tabi tutulmuştur. Bu inceleme yapılırken öncelikle sporcu sözleşmelerine ilişkin genel bilgiler verilmiş; ardından da e-spor hukuku bakımından sporcu sözleşmeleri değerlendirilmiştir.

\section{E-SPOR VE E-SPOR HUKUKU}

$\mathrm{Bu}$ başlık altında e-sporun tanımı ile e-spor hukuku hakkında genel bilgiler verilmektedir.

\section{A. E-Sporun Tanımı}

Teknolojide yaşanan hızlı gelişim ve değişimler beraberinde birtakım yenilikleri de getirmektedir. $\mathrm{Bu}$ yenilikler arasında sporun, internet ortamında yapılması sonucunu doğuran ve e-spor adı ile anılan bir spor dalı ortaya çıkmıştır. E-Spor ya da açık ifadeyle elektronik spor, dijital veya internet ortamında, takım halinde ya da bireysel olarak amatör-profesyonel düzeyde oynanan ve kendine has kurallara sahip olan bir spor dalıdır ${ }^{4}$ 25.09.2018 tarihinde yayımlanan E-Spor Federasyonu Sporcu, Lisans, Tescil, Vize ve Transfer Talimatı'nın "Tanımlar" başlığını taşıyan 4. maddesinin (f) bendinde de e-spor, "Elektronik bir cihaz vasıtasıla çevrimiçi ve çevrimdışı ortamda gerek bireysel gerekse takım halinde katılım gösterilen her türlü aktivite" şeklinde ifa edilmektedir.

E-sporda, diğer spor dallarına oranla sporcuların hareketleri fiziksel olmaktan ziyade taktiksel ve zihinsel olup fiziki anlamda bir efor harcanmamaktadır ${ }^{5}$. Bu

4 YÜKÇÜ, Süleyman/KAPLANOĞLU, Emre; “e-Spor Endüstrisi”, Uluslararası İktisadi ve İdari İncelemeler Dergisi, 17. UİK Özel Sayıs1, 2018, s. 535; WAGNER, Michael G.; "On the Scientific Relevance of eSports", https://www.researchgate.net/publication/220968200, Erişim Tarihi: 19.09.2018, s. 3. E-sporun, bir spor dalı olarak değerlendirilebileceği noktasinda bkz., "Die Zukunft des e-Sports-Teil 1", http://sportrechtblog.de/die-zukunftdes-e-sports-teil-1/, Erişim Tarihi: 26.09.2018. Ayrica bkz., BREUER, Markus; "Einleitung: Ein multidisziplinärer Blick auf den elektronischen Sport", E-SportPerspektiven aus Wissenschaft und Wirtschaft, Ed: Markus Breuer, Verlag Werner Hülsbusch, 2012, s. 7 vd. E-sporun çeşitli tanımları için bkz., BREUER, Markus; eSporteine Markt- und ordnungsökonomische Analyse, Diss., 2011, s. 6, (E-Sport); LAAKKONEN, Juuso; Business Models In Esports, Thesis, Turku University of Applied Sciences, 2014, s. 19.

5 Bu noktada e-sporun, gerçek anlamda bir spor branşı olup olmadığı tartışmaları da sürmektedir. Konuya ilişkin bkz., "E-Spor ve Türkiye”, https://www.e-sporhukuku.com/espor-ve-turkiye/, Erişim Tarihi: 19.09.2018. 
noktada kanaatimce e-sporda zihinsel antrenman daha büyük bir rol oynamaktadır ${ }^{6}$. Ayrıca e-spor, internet ortamında olduğundan dolayı daha geniş kitlelere ulaşmakta; bir bakıma bütün dünyayı tek bir platformda buluşturmaktadır? .

E-spor kendisini daha çok bilgisayar oyunlarında göstermektedir. Tarihsel süreçte e-spor ilk defa 1990 yılların sonunda ortaya çımış ${ }^{8}$ ve hızlı bir gelişim göstermiştir. Türkiye'de de özellikle genç nüfusta ilgi odağı haline gelen e-spor için bazı düzenlemeler yapılmıştır. 2011 yılında Türkiye Dijital Oyunlar Federasyonu adı altında bir federasyon kurulmuş ancak 2013 yılında Gelişmekte Olan Spor Branşları Federasyonu kapsamına alınarak lağvedilmiştir. Bununla birlikte e-spor için 24/04/2018 tarihli ve 277144 sayılı Bakanlık Oluru ile Türkiye E-Spor Federasyonu ${ }^{9}$ kurulmuştur ${ }^{10}$. TESFED'nin resmî internet sitesinde e-spor açısından MOBA (Çevrimiçi Çok Oyunculu Savaş Arenası) $^{11}$, FPS (Birinci Şahıs Nişancı) ${ }^{12}$, RTS (Gerçek Zamanlı Strateji Oyunu) ${ }^{13}$, Battle Royale ${ }^{14}$, SPOR ${ }^{15}$, MMORPG (Massively

6 Zihinsel antrenman ve bunun sporla ilişkisi açısından ayrıntılı bilgi için bkz., AKANDERE, Mehibe/AKTAŞ, Samet/ER, Yusuf; "Zihinsel Antrenman ve Spor”, Özdemir Özok Armağanı, Ed: Tacar Çağlar, Türkiye Barolar Birliği Yayınları, 2018, s. 4 vd.

7 Ayrica bkz., TOMECKA, Małgorzata; "Sport, including e-sport, in the light of various interpretations", Spor Bilimleri Araştırmaları Dergisi, Journal of Sport Sciences Researches, C.2, S.2, 2017, s. 22.

8 E-sporun tarihsel süreçteki gelişimi noktasında ayrıntılı bilgi için bkz., ÜÇÜNCÜOĞLU, Mertkan/ÇAKIR, Veli Ozan; "Modern Spor Kulüplerinin Espor Faaliyetlerine İlgi Gösterme Nedenleri Üzerine Bir Araştırma”, İnönü Üniversitesi, Beden Eğitimi ve Spor Bilimleri Dergisi, C.4, S.2, 2017, s. 36 vd.; YÜKÇÜ/KAPLANOĞLU, s. 536-537. Ayrıca bkz., "Dünden Bugüne E-Spor Tarihi", https://www.e-sporhukuku.com/e-spor-tarihi/, Erişim Tarihi: 19.09.2018.

9 Bundan sonra TESFED şeklinde ifade edilecektir.

10 Türkiye E-Spor Federasyonu sayfasına, http://tesfed.gov.tr adresinde ulaşılabilir.

11 Çevrimiçi çok oyunculu savaş arenası ya da MOBA, bir gerçek zamanlı strateji savaş video oyunu türüdür. Genellikle beş kişiden oluşan iki farklı takımın üç ana yoldan oluşan bir harita üzerinde karşı takımın enerji kaynağını yok etmeyi amaçlar.

12 Birinci şahıs nişancı oyuncu karakterinin kendi gözünden oynandığı oyun türüdür ve nişanc1 video oyunlarının yan türüdür. Tüm nişan türündeki oyunlar gibi, "bir serüven, bir veya birden fazla uzun menzilli silah ve değişen sayılarda düşmanlar" tabiriyle anılır.

13 Gerçek zamanlı strateji oyunları, oyuncuların birbirlerinin sırasını beklemeden devamlı olarak karşılıklı oynamaya devam ettikleri bilgisayar oyunları. Bunun aksi olan sıra tabanlı strateji oyunlarında oyuncular hamle yapabilmek için karşı tarafın hamlesini beklemek zorundadirlar.

14 Battle Royale olarak denildiğinde akıllarda temel olarak canlanan terim hayatta kalma olarak adlandırabiliriz. Bir alanda belirli sayıda düşman ve hayatta kalmaya çalışmak. Gerektiğinde saldırmak, gerektiğinde saklanmak. Hayatta kalmak için her şeyi yapmaya hazır olmak. İşte bu düşüncelerin hepsinin Battle Royale oyunlarda olduğunu düşünün. Tabii kısaca Battle Royale; açlık, susuzluk, dayanıklılık gerektirmeyen ve haritada canlı kalabilen son kişi olmayı hedeflediğiniz bir oyun modudur.

15 Geleneksel spor dallarının, sanal ortama uyarlanmış halleridir. 
Multiplayer Online Role Playing Game-Çok Katılımcılı Çevrimiçi Rol Yapma Oyunu) ${ }^{16}$ ve FIGHTER ${ }^{17}$ branşlarına yer verildiği görülmektedir.

\section{B. E-Spor Hukuku}

E-spor ile birlikte bu spor dalının belli kurallar çerçevesinde yapılması ihtiyacı gündeme gelmiştir. Bu noktada e-spor hukuku adı altında yeni bir spor hukuku dalı ortaya çıkmıştır. E-spor hukukunun tanımını vermek gerekirse, e-spor adı altında yapılan faaliyetlerin belirli kurallar çerçevesinde ilerlemesini sağlayan ve e-spor süjeleri arasındaki ilişkileri de düzenleyen yeni bir spor hukuku alt dalıdır.

E-spor hukukuna bakıldığında onun çok çeşitli inceleme alanları olduğu söylenebilir. Bunlardan ilki ve belki de en önemlisi makalenin de konusunu oluşturan e-spor sporcu sözleşmeleridir. Sporcu sözleşmeleri dişında ceza hukuku ile 6222 Sayılı Sporda Şiddet ve Düzensizliğin Önlenmesine Dair Kanunu ilgilendiren şike suçunun e-spor arenasında kendisini göstermesi mümkün olabilmektedir. Bununla birlikte sponsorluk, fikri ve sinai haklar kapsamında da e-spor hukukunun bağlantısının bulunduğu söylenebilir.

\section{E-SPOR HUKUKU AÇISINDAN SPORCU SÖZLEŞMELERİ}

E-spor hukuku açısından sporcu sözleşmeleri incelenmeden önce, genel olarak sporcu sözleşmelerine ilişkin bilgiler verilmişstir.

\section{A. Genel Olarak Sporcu Sözleşmeleri}

Sporcu sözleşmeleri sporcu ile spor kulübü arasında imzalananın, sporcunun ilgili spor branşında sportif başarılar elde etmeyi ve bunun karşılığında da spor kulübünden belli bir miktar ücret aldığı spor hukuku sözleşmesidir ${ }^{18}$. Spor Hukuku bakımından sporcuların profesyonel ve amatör olmak üzere ikiye ayrıldığı görülmektedir ${ }^{19}$. Buradan hareketle sporcu sözleşmelerinin de profesyonel sporcu sözleşmesi ve amatör sporcu sözleşmesi şeklinde ayrılması mümkündür. Türkiye'de sadece futbol branşı "profesyonel" olarak kabul edildiği için ${ }^{20}$ profesyonel futbolcu

16 Herhangi bir sunucuya bağlanarak oynanan rol yapma oyunlarıdır.

17 Oyuncu belli bir dövüş disiplinini temsil eden, seçtiği sanal karakterler ile diğer oyuncuların seçtiği diğer sanal karakterlere üstün gelmeye çalışır. Yaygın olarak bir oyuncuya karşı bir oyuncu şeklinde oynanır.

18 Ayrıca bkz., AYDOS, Oğuz Sadık; "Sporcu Sözleşmesinin Feshi”, Ankara Üniversitesi Hukuk Fakültesi Dergisi, C.62, S.3, 2013, s. 645; HARDAL, Şekip; "Spor Sözleşmeleri”, İstanbul Barosu Dergisi-Spor Hukuku Özel Sayıs1, 2007, s. 94-95; GENÇ, s. 69; ERTAŞ/PETEK, s. 396.

19 AYDOS, s. 645.

20 Bkz., KÜÇÜKGÜNGÖR, Erkan; "Türk Hukukunda Sporcuların Hukuki Durumu”, Ankara Barosu Dergisi, 1999/1, s. 40; ÖZELÇi, Aytaç; Türkiye Futbol Federasyonu'nun Türk Hukukundaki Yeri, Seçkin Yayıncılık, 2010, s. 78. 
sözleşmesinden bahsedilir ${ }^{21}$. Sporcu sözleşmelerinde ilgili branşın sporcusu, bütün gücü ve gayretiyle hem kendi hem de kulübün başarısı için ter dökmektedir. Kulüp de sporcusuna sözleşmede belirlenen ücreti ödeme yükümlülüğü altındadır.

Sporcu sözleşmelerinin hukuki niteliği konusunda farklı değerlendirmelerde bulunmak mümkündür ${ }^{22}$. Özellikle iş görme amacı güden sözleşmelere ait birtakım durumlar, sporcu sözleşmelerine uymaktadır. Ancak kanaatimce sporcu sözleşmelerini, spor hukuku sözleşmesi olarak kabul etmek ve ilgili federasyonlar tarafından çıkarılan talimatlar doğrultusunda ortaya çıkan uyuşmazlıkların giderilmesi gerekmektedir.

\section{B. E- Spor Hukuku Kapsamında Sporcu Sözleşmelerinin Değerlendirilmesi}

E-spor sporcu sözleşmesine ilişkin genel bilgiler ile sözleşme kapsamında tarafların hak ve yükümlülüklerine değinilmektedir.

\section{Sözleşmeye İliş̧kin Genel Bilgiler}

E-spor müsabakalarına katılacak olan sporcu ile kulübü arasında bir sözleşme imzalanmaktadır. Özellikle profesyonel e-spor sporcularının, bir kulüp adı altında müsabakalara katılmaları, sözleşme yapma zorunluluğunu da gündeme getirmektedir. Ancak hemen belirtmek gerekir ki henüz e-sporda sporcular açısından diğer spor branşlarının aksine matbu bir sözleşme yoktur ${ }^{23}$. Ayrıca TESFED tarafından e-sporun esaslarını düzenleyen bir talimat da şu an için bulunmamaktadır. Bütün bunların varlığı (sözleşmenin sağlam bir zemine oturtulamaması) e-spor sporcusu ile kulübü arasında yapılacak olan sözleşmede bazı problemlerin doğmasına sebebiyet verebilir. Bütün dünyada olduğu gibi ülkemizde de büyük kitleleri peşinden sürüklemeye başlayan e-spor branşı, yasal bir zemine oturtulmalıdır.

Türkiye'de profesyonel olarak sadece futbol branşı kabul edildiğinden dolayı, espor sporcu sözleşmelerine, e-spor sözleşmeleri için yeni bir düzenleme getirilinceye kadar, kanaatimce profesyonel futbolcu sözleşmesine ilişkin esasların niteliği uygun düştüğü ölçüde uygulanması yerinde olur. $\mathrm{Bu}$ durum, hem sadece futbol branşının profesyonel olarak kabul edilmesi hem de e-spor sözleşmeleri açısından henüz bir yasal düzenlemenin bulunmaması noktasından gerekçelendirilebilir. Ayrıca e-spor sporcusu ile kulüp arasında bir uyuşmazlık çıktığında, bu uyuşmazlığın spor hukuku açısından çözümü de daha rahat olur.

E-spor sporcu sözleşmesi, sözleşmeye ilişkin gerekli unsurları bünyesinde barındırmak şartıyla imzalanmalı ve imzalanan sözleşme TESFED'ye tescil işleminin

21 Profesyonel futbolcu sözleşmesi açısından ayrıntılı bilgi için bkz., PETEK, Hasan; Profesyonel Futbolcu Sözleşmesi, Yetkin Yayınları, 2002, s. 34 vd.; CEM, Çă̆rı; Profesyonel Futbolcu Transfer Sözleşmesi, On İki Levha Yayıncılık, 2012, s. 17 vd.

22 Konuya ilişkin ayrıntılı bilgi için bkz., AYDOS, s. 646 vd.

23 ÖKSÜZ; Talha; "E-spor Hukuku ve Türkiye'de E-spor Hukuku Üzerine”, https://playerbros.com/espor-hukuku/, Erişim Tarihi: 21.09.2018. 
yapılabilmesi için sunulmalıdır ${ }^{24}$. Örnek oluşturması maksadıyla TESFED tarafından matbu bir sözleşmenin hazırlanması söz konusu olabilir. Sözleşmenin yapılması hususunda on sekiz yaşından küçük e-sporcular için yasal temsilcisinin izin ya da icazeti aranmalıdır.

E-spor sporcu sözleşmesinde ücrete ilişkin bir düzenlemenin bulunması gerekir. Ücret miktarının yanı sıra, ücretin ödenme biçimine ilişkin de taraflarca bir belirleme yapılmalıdır. Bu ücret, aylık ödenebileceği gibi sözleşmenin bitiminde toplu bir şekilde de ödenebilir. Ayrıca sözleşmenin süresi açısından tarafların bunu e-spor sporcu sözleşmesinde açıkça belirtmeleri yerinde olur. Bununla birlikte bir kulübün sporcusu olan e-sporcuyu transfer etmek isteyen bir başka kulübün transfer görüşmelerine başlayabilmesi için öncelikle sporcunun bağlı olduğu kulüpten izin alması son derece yerinde ve uygun olur ${ }^{25}$.

\section{Sözleşme Kapsamında Tarafların Hak ve Yükümlülükleri}

E-spor sporcu sözleşmesinde, tarafların sözleşmede kararlaştırdıkları ve üzerinde anlaştıkları hususlara uygun hareket etmeleri gerekir. Bunun dışında spor hukuku anlamında da birtakım hak ve yükümlülüklerden bahsetmek mümkündür. Espor sporcu sözleşmesine niteliği uygun düştüğü ölçüde Profesyonel Futbolcuların Statüsü ve Transferleri Talimatı'nın tarafların hak ve yükümlülüklerini düzenleyen 24 ve 25. madde hükümlerinin uygulanması kanaatimce mümkündür.

E-spor sporcu sözleşmesinde tarafların hak ve yükümlülükleri, e-sporcunun sözleşme kapsamında hak ve yükümlülükleri ile kulübün sözleşme kapsamında hak ve yükümlülükleri şeklinde iki başlık altında incelenebilir.

\section{a. E-Sporcunun Sözleşme Kapsamında Hak ve Yükümlülükleri}

E-spor branşında e-sporcunun yapması gereken şey, ilgili müsabakalara katılarak kulübü adına başarılı sonuçlar elde etmektir. Söz konusu başarıların kazanılabilmesi için e-sporcunun kendisini sürekli bir biçimde geliştirmesi ve farklı stratejiler üzerinde çalışması gerekmektedir. Ayrıca kulübün ya da TESFED’nin düzenleyeceği kurs, seminer veya konferanslara katılması şarttır ${ }^{26}$. Bunun dışında esporcunun müsabakalara katılmasını sağlayacak işlemleri takip etmesi ve gerekli belgeleri de eksiksiz bir şekilde sağlaması, onun yükümlülükleri arasındadır ${ }^{27}$.

24 Profesyonel futbolcu sözleşmesinde de tarafların imzaladığı sözleşmenin tescil amacıyla TFF'ye sunulması zorunludur. (Profesyonel Futbolcuların Statüsü ve Transferleri Talimatı Madde 19/1)

25 Söz konusu durum, profesyonel futbolcu sözleşmesi açısından da uygulanmaktadır. (Profesyonel Futbolcuların Statüsü ve Transferleri Talimatı Madde 19/6)

26 Benzer durum Profesyonel Futbolcuların Statüsü ve Transferleri Talimatı Madde 25/1-b'de de "TFF'nin ve kulübün düzenlediği kurs, ders ve konferanslara katılmak" şeklinde profesyonel futbolcular için düzenlenmektedir.

27 Ayrıca bkz., Profesyonel Futbolcuların Statüsü ve Transferleri Talimatı Madde 25/1-a. 


\section{b. Kulübün Sözleșme Kapsamında Hak ve Yükümlülükleri}

Kulübün öncelikli yükümlülüğü, e-sporcuların müsabakalara en iyi şekilde hazırlanması sağlamak ve bu açıdan uzman teknik adamlar ile gerekli her türlü malzemenin temin edilmesidir ${ }^{28}$. E-spor branşı açısından son teknoloji bilgisayar malzemelerinin alınması, teknik anlamda en hızlı ve gelişmiş sistemlerin kurulması ve bunların kullanılmasının sağlanması gerekmektedir. Ayrıca söz konusu yeni sistemlere ilişkin olarak gerekli eğitimlerin verilmesi, bu eğitimlerin uygulamalı olarak gösterilmesi de kulübün sorumlulukları arasında yer almaktadır.

\section{Sözleşmenin Sona Ermesi}

E-spor sporcu sözleşmelerinin sona ermesi değişik şekillerde ortaya çıkabilir. Bunlardan ilki e-sporcu ile kulübünün karşlıklı anlaşmak suretiyle sözleşmeyi sona erdirme imkânıdır. E-spor sporcu sözleşmesi kapsamında e-sporcu ile kulüp sözleşmenin sona erdirilmesi hususunda anlaşmaya varırlarsa, söz konusu sözleşme ortadan kalkar. Sözleşmenin karşıllklı sona erdirilmesi yanında şayet taraflar sözleşmeyi bir süreye bağlamışlarsa, bu sürenin bitimiyle de sözleşme sona ermiş olur.

E-spor sporcu sözleşmesi, e-sporcu ya da kulübün fesih hakkını kullanması ile sona erebilir. Bu noktada hangi hallerde fesih hakkının kullanılabileceği TESFED tarafından konuya ilişkin henüz bir düzenleme getirilmediği için belirlenememektedir. Bu noktada feshe ilişkin genel bilgiler yanında Profesyonel Futbolcuların Statüsü ve Transferleri Talimatı kapsamındaki fesih sebeplerinin niteliği uygun düştüğü ölçüde uygulama alanı bulması mümkündür. Profesyonel Futbolcuların Statüsü ve Transferleri Talimatı'nda sözleşmenin feshi, kulübün fesih hakkı ve futbolcunun fesih hakkı olmak üzere iki ayrı maddede tespit edilmiştir.

E-spor sporcu sözleşmesinde sporcunun fesih hakkını kullanabilmesi öncelikle ücretinin ödenmemesi durumunda kendini gösterir ${ }^{29}$. E-sporcuya ödenmesi kararlaştırılan ücretin kulüp tarafından zamanında ya da hiç ödenmemesi durumunda, e-sporcunun sözleşmesini feshetme hakkı vardır. Bununla birlikte e-sporcu sözleşmesinde yer alan ve kulübün sözleşmeden kaynaklanan yükümlülüklerini yerine getirmemesi hâlinde de e-sporcunun sözleşmesini feshetme hakkına sahip olması gerekir.

E-spor sporcu sözleşmesinde kulübün de sözleşmeyi feshetme hakkı vardır. Örneğin e-sporcu şike yapmak suretiyle belli süreler müsabakalardan men cezası almışsa burada kulübün, sözleşmeyi feshetme hakkı gündeme gelir ${ }^{30}$. Bunun yanı sıra

28 Benzer şekilde bkz., Profesyonel Futbolcuların Statüsü ve Transferleri Talimatı Madde 24/1-a ve b.

29 Profesyonel Futbolcuların Statüsü ve Transferleri Talimatı'na göre de futbolcunun ücretinin ödenmemesi durumunda futbolcunun sözleşmeyi feshetme hakkı bulunmaktadır.

30 Profesyonel Futbolcuların Statüsü ve Transferleri Talimatı'na göre futbolcunun en az altı ay süreyle müsabakadan men cezası alması durumunda sözleşmesi kulüp tarafından 
sözleşmede kararlaştırılan ancak e-sporcunun bu yükümlülüklere aykırı hareketlerde bulunması durumunda da kulübün sözleşmeyi feshetmesi mümkündür.

\section{SONUÇ}

E-spor adı altında ortaya çıkan ve dünyada özellikle gençleri etkisi altına alan bu spor branşının, belirli kurallar çerçevesinde yapılması ihtiyacı sebebiyle e-spor $h u k u k u$ adı altında genç ve yeni bir spor hukuku alt dalı doğmuştur.

E-spor sporcu sözleşmeleri, e-spor sporcusu ile kulübü arasında imzalanan bir spor hukuk sözleşmesidir. Bu sözleşmeye ilişkin olarak henüz TESFED tarafından çıkarılmış bir talimat ya da düzenleme bulunmamaktadır. Kanaatimce e-spor sporcu sözleşmesine ilişkin TESFED tarafından bir düzenleme çıkarılıncaya kadar, Profesyonel Futbolcuların Statüsü ve Transferleri Talimatı'nda düzenlenen profesyonel futbolcu sözleşmesine ilişkin hükümlerin, niteliği uygun düştüğü ölçüde e-spor sporcu sözleşmelerine uygulanmasında herhangi bir sakınca bulunmamaktadır. Gerekçe olarak ülkemizde sadece futbol branşının profesyonel olarak kabul edilmesi ile yeni bir düzenleme yapılıncaya kadar e-spor sporcu sözleşmelerinin yasal bir zemine oturtulmasının daha doğru sonuçlar vereceği düşüncesi gösterilebilir. $\mathrm{Bu}$ açıdan geçici bir süreyle de olsa e-spor sporcu sözleşmeleri açısından uygulanması mümkün birtakım hükümlerin varlığından da söz edilebilecektir. Ancak bir an önce TESFED tarafından e-spor sporcu sözleşmelerine ilişkin, içinde sözleşmenin yapılması usul ve esaslarının yer aldığı bir düzenlemenin çıkarılması gerekmektedir.

feshedilebilir. Futbolcular için ön görülen bu süre, e-spor sporcu sözleşmeleri açısından daha kısa tutulabilir. 


\section{KAYNAKÇA**}

AKANDERE, Mehibe/AKTAŞ, Samet/ER, Yusuf; "Zihinsel Antrenman ve Spor", Özdemir Özok Armağanı, Ed: Tacar Çağlar, Türkiye Barolar Birliği Yayınları, Ankara 2018, s. 1-16.

AKYILDIZ, Ali; “Sporun Hukuku ve Yargısı", Ömer Remzi Arıkan Armağanı, Ed: Tacar Çağlar, Mattek Matbaacılık, Ankara 2013, s. 59-116.

AYDIN, Zübeyt; "Spor ve Spor Politikalart", Ankara Barosu Spor Hukuku Kurulu Av. Akın Ataksoy Armağanı, Ed: Tacar Çağlar, Afşaroğlu Matbaası, Ankara 2015, s. 177-311.

AYDOS, Oğuz Sadık; "Sporcu Sözleşmesinin Feshi", Ankara Üniversitesi Hukuk Fakültesi Dergisi, C.62, S.3, 2013, s. 643-689.

BREUER, Markus; eSport-eine Markt- und ordnungsökonomische Analyse, Diss., 2011, (E-Sport).

BREUER, Markus; "Einleitung: Ein multidisziplinärer Blick auf den elektronischen Sport", E-Sport-Perspektiven aus Wissenschaft und Wirtschaft, Ed: Markus Breuer, Verlag Werner Hülsbusch, Glückstadt 2012, s. 7-10.

CEM, Çağrı; Profesyonel Futbolcu Transfer Sözleşmesi, On İki Levha Yayıncılık, İstanbul 2012.

ÇAĞLAYAN, Ramazan; Spor Hukuku (Spor Hukuku Temel Metinleri), Asil Yayın Dağıtım, Ankara 2007.

EKŞi, Nuray; Spor Tahkim Hukuku, Beta Basım Yayım Dağıtım, İstanbul 2015.

ERDEMLI, Attilla; “Spor Nedir?”, Spor Hukuku Dersleri, Ed: Kismet Erkiner/Ali Soysüren, Kadir Has Üniversitesi Yayınları, 2007, s. 11-20.

ERKIINER, Kısmet; “Türkiye'de Spor Hukuku'nun Oluşumu”, İstanbul Barosu Dergisi-Spor Hukuku Özel Sayısı, 2007, s. 17-40.

ERTAŞ, Şeref/PETEK, Hasan; Spor Hukuku, Yetkin Yayınları, B.3, Ankara 2017.

ERTEN, Rifat; Milletlerarası Özel Hukukta Spor, Adalet Yayınevi, Ankara 2007.

ERTEN, Rifat; “Türk Sporunun Yapısal Düzeni”, Gazi Üniversitesi Hukuk Fakültesi Dergisi, C.X, S.1,2, 2006, s. 117-136, (Yapısal Düzen).

FRITZWEILER, Jochen/PFISTER, Bernhard/SUMMERER, Thomas; Praxishandbuch Sportrecht, C.H. Beck Verlag, 3. Aufl., München 2014.

GENÇ, Durmuş Ali; Spor Hukuku, Alfa Basım Yayım Dağııım, İstanbul 1998.

\footnotetext{
** Birden fazla yayını olan ya da aynı soyadını taşıyan ve bunlara yollama yapılan yazarların eserleri için dipnotlarda parantez içinde kısaltmalar kullanılmıştır.
} 
GÜLŞEN, Recep; Spor Hukuku, Adalet Yayınevi, B.2, Ankara 2013.

HARDAL, Şekip; "Spor Sözleşmeleri”, İstanbul Barosu Dergisi-Spor Hukuku Özel Sayı1, 2007, s. 93-102.

KILCIGILL, Ertan; Sosyal Çevre-Spor İlişkileri (Teori ve Elit Sporculara İlişkin Bir Uygulama), Bağırgan Yayınevi, Ankara 1998.

KÜÇÜKGÜNGÖR, Erkan; "Türk Hukukunda Sporcuların Hukuki Durumu", Ankara Barosu Dergisi, 1999/1, s. 39-52.

LAAKKONEN, Juuso; Business Models In Esports, Thesis, Turku University of Applied Sciences, 2014

ÖKSÜZ; Talha; "E-spor Hukuku ve Türkiye'de E-spor Hukuku Üzerine”, https://playerbros.com/espor-hukuku/, Erişim Tarihi: 21.09.2018.

ÖZELÇi, Aytaç; Türkiye Futbol Federasyonu'nun Türk Hukukundaki Yeri, Seçkin Yayıncilık, Ankara 2010.

PETEK, Hasan; Profesyonel Futbolcu Sözleşmesi, Yetkin Yayınları, Ankara 2002.

TOMECKA, Małgorzata; "Sport, including e-sport, in the light of various interpretations", Spor Bilimleri Araştırmaları Dergisi, Journal of Sport Sciences Researches, C.2, S.2, 2017, s. 21-29.

TÜKENMEZ, Metin; Toplumbilim ve Spor, Kaynak Yayınları, B.2, İstanbul 2011.

ÜÇÜNCÜOĞLU, Mertkan/ÇAKIR, Veli Ozan; "Modern Spor Kulüplerinin Espor Faaliyetlerine Illgi Gösterme Nedenleri Üzerine Bir Araştırma", İnönü Üniversitesi, Beden Eğitimi ve Spor Bilimleri Dergisi, C.4, S.2, 2017, s. 34-47.

WAGNER, Michael G.; "On the Scientific Relevance of eSports", https://www.researchgate.net/publication/220968200, Erişim Tarihi: 19.09.2018, s. 1-4.

YÜKÇÜ, Süleyman/KAPLANOĞLU, Emre; "e-Spor Endüstrisi”, Uluslararası İktisadi ve İdari İncelemeler Dergisi, 17. UíK Özel Sayısı, 2018, s. 533-550.

\section{Elektronik Kaynaklar}

"Dünden Bugüne E-Spor Tarihi", https://www.e-sporhukuku.com/e-spor-tarihi/, Erişim Tarihi: 19.09.2018.

"E-Spor ve Türkiye”, https://www.e-sporhukuku.com/e-spor-ve-turkiye/, Erişim Tarihi: 19.09.2018.

"Die Zukunft des e-Sports-Teil 1", http://sportrechtblog.de/die-zukunft-des-e-sportsteil-1/, Erişim Tarihi: 26.09.2018. 
